\title{
Copper-basic sites synergic effect on the ethanol dehydrogenation and condensation reactions
}

\author{
Jorge Quesada, Laura Faba, Eva Díaz, and Salvador Ordóñez*
}

\begin{abstract}
Bioethanol upgrading via condensation is of key interest in the development of sustainable processes, shifting fossil by renewable carbon. We propose a new strategy, combining in one catalyst an appropriate distribution of acid/basic sites of a mixed oxide with the presence of an active dehydrogenation phase $(\mathrm{Cu}$ nanoparticles). Experiments, performed in a fixed bed reactor, reveal a very positive effect of $\mathrm{Cu}$ in the performance of $\mathrm{Mg}$-Al catalyst, with 1-butanol productivity 12 times higher at $523 \mathrm{~K}$ under inert conditions The improvement is even more notable in presence of $\mathrm{H}_{2}$, being almost 30 times higher, at same conditions. The presence of $\mathrm{Cu}$ on the surface increases the formation of acetaldehyde, limiting the extent of dehydration side-reactions. In addition, hydrogen enhances the C4 hydrogenation, preventing oligomerizations and inhibiting decarbonylation steps that are directly related to the catalytic deactivation by poisoning.
\end{abstract}

\section{Introduction}

The dehydrogenation of alcohols to aldehydes and ketones is one of the most important steps in the field of the production of added-value chemicals from alcohols. ${ }^{[1]}$ Concerning primary alcohols $\left(\mathrm{R}-\mathrm{CH}_{2}-\mathrm{OH}\right)$ and heterogeneous catalysis, the corresponding aldehydes obtained by dehydrogenation interact with the catalytic surface, resulting in the formation of intermediate moieties, such as enolates $\left(\mathrm{R}-\mathrm{CH}^{*}-\mathrm{CH}=\mathrm{O}\right)$ and acyls $\left(\mathrm{R}-\mathrm{CH}_{2}-\mathrm{C}^{*}=\mathrm{O}^{*}\right)$. These surface intermediates are energetically stabilized by acid-basic pair sites or metal nanoparticles. ${ }^{[2,3]}$ Subsequently, these species can undergo the formation of $\mathrm{C}-\mathrm{C}$ and $\mathrm{C}-\mathrm{O}$ bonds by aldol condensation and esterification reactions, respectively, leading to larger oxygenates with higher value as chemical precursors. ${ }^{[3,4]}$ Consequently, catalytic dehydrogenation has a high upgrading potential for biomass-derived compounds, such as ethanol.

Ethanol upgrading is accomplished via different reactions, ${ }^{[5]}$ being the Guerbet reaction one of the most widely proposed. ${ }^{[6]}$ This reaction enables to obtain higher alcohols, 1-butanol in this case, from two shorter alcohols (ethanol) via aldol condensation. ${ }^{[7]}$ Essentially, the Guerbet reaction consists of four steps (alcohol dehydrogenation to corresponding aldehyde, aldolization of the aldehyde followed by dehydration of the formed aldol, and two hydrogenations of the respective $\alpha, \beta$-unsaturated aldehyde yielded in the previous step) shown in

J. Quesada, Dr. L. Faba, Dr. E. Díaz, Prof. S. Ordóñez

Department of Chemical and Environmental Engineering

University of Oviedo

Av. Julián Clavería s/n, Oviedo, 33006 (Spain)

E-mail: sordonez@uniovi.es

Supporting information for this article can be found under:

Scheme $1 .{ }^{[7,8]}$ According to this complex mechanisms, there is not agreement about the key step of the process. Several authors highlight the aldolization step (C-C bond formation) as the key step, focusing the efforts in the development of active catalysts with acid/basic pairs. ${ }^{[8,9]}$ By contrast, other researchers suggest that the whole process is conditioned by the first abstraction of the $\mathrm{aH}$, because of the higher activation energy barrier of this step in comparison to the aldolization one, requiring higher temperatures to take place ${ }^{[7]}$ Considering both perspectives, modifying the acid-base catalysts (such as basic mixed oxides) by supporting metal nanoparticles (with demonstrated dehydrogenation activity) on their surface would allow improving this first step and, as a consequence, the performance of the whole process. Copper has been reported as the most selective metal promoting alcohol dehydrogenation. ${ }^{[10]}$ In recent works, ${ }^{[11-13]}$ some authors used copper supported on metal oxides $\left(\mathrm{CeO}_{2}\right.$ and $\left.\mathrm{ZrO}_{2}\right)$ in the ethanol upgrading with the aim of improving the 1-butanol or ethyl acetate production obtaining satisfactory results. Nevertheless, the copper loadings ( $\geq 5 \mathrm{wt}$. \%) were fairly high, ${ }^{[11-13]}$ masking the effect of the acid and basic site of the oxide. There are also works concerning this reaction in which other transition metals (e.g., iron, nickel,

$$
\begin{aligned}
& \underset{\text { diethyl ether }}{\left(\mathrm{C}_{2} \mathrm{H}_{5}\right)_{2} \mathrm{O}} \underset{-\mathrm{H}_{2} \mathrm{O}}{+\mathrm{C}_{2} \mathrm{H}_{6} \mathrm{O}} \quad \begin{array}{l}
\mathrm{C}_{2} \mathrm{H}_{6} \mathbf{O} \\
\text { ethanol }
\end{array} \underset{-\mathrm{H}_{2} \mathrm{O}}{\longrightarrow} \begin{array}{c}
\mathrm{C}_{2} \mathrm{H}_{4} \\
\text { ethylene }
\end{array} \\
& -\mathrm{H}_{2} \mid \downarrow+\mathrm{H}_{2} \\
& \underset{\text { acetaldehyde }}{\mathbf{C}_{\mathbf{2}} \mathrm{H}_{\mathbf{4}} \mathbf{O}} \stackrel{+\mathrm{C}_{2} \mathrm{H}_{4} \mathrm{O}}{\longrightarrow} \underset{\text { ethyl acetate }}{\mathrm{C}_{4} \mathrm{H}_{8} \mathrm{O}_{2}} \\
& -\mathrm{H}_{2} \mathrm{O} \downarrow+\mathrm{C}_{2} \mathrm{H}_{4} \mathrm{O} \\
& \mathbf{C}_{4} \mathbf{H}_{6} \mathbf{O} \\
& \text { crotonaldehyde }
\end{aligned}
$$

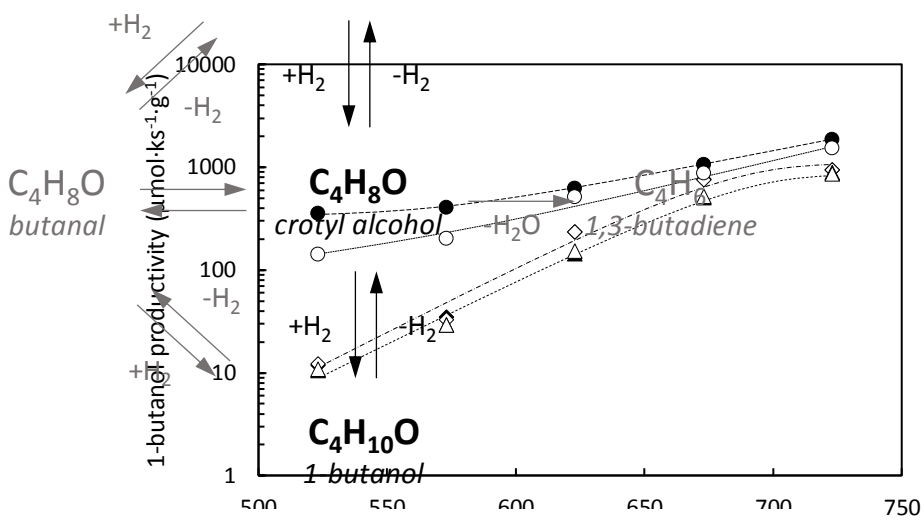

Scheme 1. Proposed reaction mechanism in the ethanol condensation. ${ }^{[7,8]}$ The Guerbet reaction is the main pathway (indicated in black and bold); side reactions are depicted in grey. 
cobalt) were supported on different oxides $\left(\mathrm{CeO}_{2}\right.$ and $\left.\mathrm{MgAlO}\right)$, but again with a relative high metal content $(5-10 \mathrm{wt} . \%) .{ }^{[14]}$

The role of the addition of $\mathrm{Cu}$ nanoparticles on the performance of magnesia-alumina mixed oxides (Mg-Al) used as catalyst for the ethanol gas-phase Guerbet reaction to 1-butanol is studied in this paper. Mg-Al was chosen as support because of its well-known behavior for the ethanol condensation (allowing discerning the real effect of Cu nanoparticles),${ }^{[15-17]}$ as well as its reasonable good activity comparing other materials tested in this reaction. ${ }^{[18]}$ Low metal loadings (1 wt. \%) were used in order to minimize the blockage and modification of the original acid/basic sites distribution of the parent mixed oxide.

In order to get a better understanding of the role of this metal, results achieved with the $\mathrm{Cu} / \mathrm{Mg}-\mathrm{Al}$ material were compared with those reached with copper supported on an inert material $\left(\mathrm{Cu} / \mathrm{SiO}_{2}\right)$ and a physical mixture of $\mathrm{Cu} / \mathrm{SiO}_{2}$ and $\mathrm{Mg}-\mathrm{Al}$ mixed oxide. Gas chromatography and in situ infrared spectroscopic (Diffuse Reflectance Infrared Fourier Transform Spectroscopy, DRIFTS) techniques were used for analyzing the different compounds yielded during the reaction, as well as their interaction with the catalyst surface.

\section{Results and Discussion}

Experiments were selected in order to have a better understanding of the synergic effect of copper and acid-basic sites distribution of the parent basic mixed oxide, also considering the role of the copper nanoparticles in the hydrogen activation. Thus, three different catalysts were studied: parent Mg-Al mixed oxide, copper supported in this oxide, and a physical mixture of the oxide with $\mathrm{Cu} / \mathrm{SiO}_{2}$ catalyst $\left(\mathrm{SiO}_{2}\right.$ is considered to have negligible acid-base activity, as it is also demonstrated in the characterization section). All the catalysts were tested both, in presence and in absence of hydrogen. The maximum temperature considered was $723 \mathrm{~K}$, in order to discard the copper nanoparticles sintering.

Figure 1 shows the 1-butanol productivity, under inert or reducing atmosphere, as function of the reaction temperature. In absence of hydrogen, the highest butanol production-rates were obtained with the bifunctional material $(\mathrm{Cu} / \mathrm{Mg}-\mathrm{Al})$, being the differences more relevant at soft conditions. This rate reaches a maximum of $1600 \mu \mathrm{mol} \cdot \mathrm{ks}^{-1} \cdot \mathrm{g}^{-1}$ at $723 \mathrm{~K}$. This value corresponds to a $37.1 \%$ of conversion and $25.0 \%$ butanol selectivity. If hydrogen is fed, results with $\mathrm{Cu} / \mathrm{Mg}-\mathrm{Al}$ are even better, observing improvements up to $150 \%$ when results at $523 \mathrm{~K}$ are compared). Considering that hydrogen obtained during dehydrogenation step is stoichiometrically enough to accomplish the hydrogenations, the different behavior observed under inert or reducing atmosphere suggests that hydrogen atoms released in the first step (ethanol dehydrogenation) are not efficiently used in the hydrogenation steps, recombining itself and desorbing as molecular hydrogen when working under inert atmosphere.

It can be presumed that results obtained with $\mathrm{Cu} / \mathrm{Mg}-\mathrm{Al}$ could be partially limited by the lack of acid/basic sites (supporting metals affects to the original distribution of acidity and basicity). Thus, the activity of a physical mixture of the two catalysts was considered (Mg-Al for the acid/basic sites, and $\mathrm{Cu} / \mathrm{SiO}_{2}$ for the dehydrogenation/hydrogenation steps). With this approach, the role of metal could be analyzed preventing any change in the original surface chemistry of the mixed oxide. Results are also considered in Figure 1. In this case, the productivity of 1-butanol was calculated taking into account only the mass of Mg-Al. This was considered in view of the results obtained when using $\mathrm{Cu} / \mathrm{SiO}_{2}$ for the reaction, as it is explained below.

Comparing the trends of $\mathrm{Cu} / \mathrm{Mg}-\mathrm{Al}$ and the physical mixture, it can be concluded that the expected improvement was not reached, obtained better results with $\mathrm{Cu} / \mathrm{Mg}-\mathrm{Al}$, even in absence of hydrogen. This fact highlights the key role of the spatial proximity between the metal-phase and the acid-basic active sites. In the physical mixture, the hydrogen atoms produced during the dehydrogenation (on the $\mathrm{Cu} / \mathrm{SiO}_{2}$ ) cannot react with crotonaldehyde obtained on the $\mathrm{Mg}-\mathrm{Al}$ (active sites in different phases), producing the recombination and desorption as inactive $\mathrm{H}_{2}$. On the contrary, in the $\mathrm{Cu} / \mathrm{Mg}-\mathrm{Al}$, the proximity between both active sites enhances the involvement of hydrogen atoms in those elementary steps leading to hydrogen-saturated molecules, such as butanol. This hypothesis is congruent with the well-known hydrogen spill-over that allows the mobility of hydrogen atoms on mixed oxides by a Grotthuss-type mechanism. ${ }^{[19]}$ Using the physical mixture, as there is not possible hydrogen spill-over, the Meerwein-Ponndorf-Verley (MPV) reduction is the main hydrogenation mechanism. ${ }^{[8}$ Because of this, the performance of the reaction, in terms of 1-butanol productivity, is the same under reducing or inert conditions. According to this assumption, the positive effect of reducing atmosphere on the behavior of the bifunctional material and the negligible effect of this parameter in the performance of the physical mixture are justified.

If the physical mixture is compared with the results of the parent $\mathrm{Mg}-\mathrm{Al}$, a very similar behavior was observed, with slight variations (highest difference observed at $623 \mathrm{~K}: 236$ and $154 \mu \mathrm{mol} \cdot \mathrm{ks}^{-1} \cdot \mathrm{g}^{-1}$ with the $\mathrm{Mg}$-Al and the physical mixture, respectively). In any case, all these values are significantly lower than those data obtained with the $\mathrm{Cu} / \mathrm{Mg}-\mathrm{Al}$, mainly at low temperatures (lowest difference observed at $673 \mathrm{~K}$, under inert conditions: 881 and $758 \mu \mathrm{mol} \cdot \mathrm{ks}^{-1} \cdot \mathrm{g}^{-1}$ with the $\mathrm{Cu} / \mathrm{Mg}-\mathrm{Al}$ and the $\mathrm{Mg}-\mathrm{Al}$, respectively). 
The high dependence of the reaction temperature in the cases of the Mg-Al and the physical mixture (comparing with the bifunctional), and its stabilization at the highest temperatures, is explained by the different surface chemistry of these materials, mainly in terms of strength of the acid and basic sites. These results suggest that there is more than one active site involved in the reactions catalyzed by $\mathrm{Mg}-\mathrm{Al}$ and the physical mixture, needing a minimum temperature to activate them, whereas in the case of the bifunctional catalyst, this effect does not take place, a linear evolution being observed.

In order to check this hypothesis, all the materials were characterized, analyzing the morphological properties as well as the surface chemistry. Main results are summarized in Table 1. Whereas the morphological properties are rather similar between both $\mathrm{Mg}-\mathrm{Al}$ and $\mathrm{Cu} / \mathrm{Mg}-\mathrm{Al}$, the distribution and concentration of the active sites reveal several differences. Concerning the acidity, most of the original acid sites are blocked by copper nanoparticles, being this effect more notable for the strongest ones. The concentration of these acid sites is much lower for the $\mathrm{Cu} / \mathrm{Mg}-\mathrm{Al}$, hence the amount of Lewis acid and acid-basic pair sites, which promote the MPV reduction, ${ }^{[20]}$ is significantly higher for the Mg-Al leading to higher ability of this material (or physical mixture) in performing this reaction. These sort of active sites are also related to non-desired dehydrations (obtaining ethylene and 1,3-butadiene). These dehydrations are more relevant over $650 \mathrm{~K}$, justifying the flat profile observed at the last points. Regarding the concentration of weak and medium strength basic sites (sites required for the aldolization step $^{[12]}$, it is similar with the two materials. On the other hand, the concentration of strong basic sites (as in the case of the acid ones) is much lower for the bifunctional catalyst, comparing with the parent $\mathrm{Mg}$-Al. This entails less ability to promote dehydration reactions by none of the two elimination mechanisms $\left(E_{1 \mathrm{CB}}\right.$ and $E_{2}$, with the strong basic and acid, respectively). ${ }^{[15]}$

In order to determine the relevance of dehydration side-reactions, the ethylene and 1,3-butadiene selectivities are shown in Figure 2. Selectivities $(\varphi)$ were calculated as it is explained in the Experimental Section. As it was expected, the selectivities to both compounds increase as temperature increases for all the catalysts, both in presence and in absence of hydrogen, being the effect of the temperature more relevant for the parent $\mathrm{Mg}-\mathrm{Al}$ and the physical mixture, in good agreement with the previous discussion. As to the role of the hydrogen on the dehydration steps, its presence only affects the behavior of the Mg-Al catalyst, suggesting a competitive adsorption of molecular hydrogen on the strong acid sites related to $\mathrm{OH}$ groups. This hypothesis was previously reported catalyzing the $\mathrm{H}_{2}-\mathrm{D}_{2}$ equilibration on magnesia and alumina oxides. $^{[21,22]}$ Nevertheless, this effect is less significant, even negligible, at the highest temperatures, as the importance of these $\mathrm{OH}$ sites is lower at increasing temperatures. ${ }^{[2]}$ For instance, with $\mathrm{Mg}-\mathrm{Al}$, under $600 \mathrm{~K}$ (conditions at which conversion of the different catalysts are more similar) there are

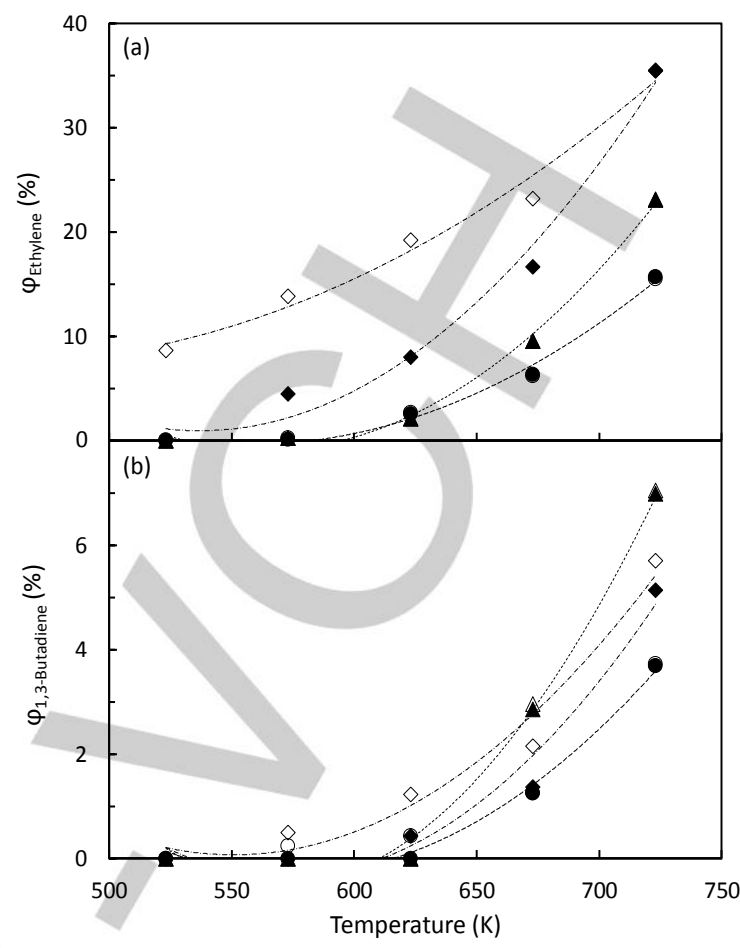

Figure 2. Selectivity evolution of the dehydration products: (a) ethylene and (b) 1,3-butadiene, with the temperature under reducing and inert conditions using: $\mathrm{Mg}-\mathrm{Al}{ }^{*}(\bullet), \mathrm{Cu} / \mathrm{Mg}-\mathrm{Al}(\bullet)$, and $\mathrm{Cu} / \mathrm{SiO}_{2}+\mathrm{Mg}-\mathrm{Al}(\mathbf{\Lambda})$. Black symbols: reducing conditions $\left(20 \mathrm{NmL} \cdot \mathrm{min}^{-1} 10 \mathrm{vol}\right.$. \% $\left.\mathrm{H}_{2} / \mathrm{He}\right)$; white symbols: inert conditions $\left(20 \mathrm{NmL} \cdot \mathrm{h}^{-1}\right.$ of $\left.\mathrm{He}\right) .{ }^{*}$ Values under inert conditions are obtained from reference [17]

significant differences in the selectivity to ethylene (Figure 2a; 13.8 and $4.5 \%$ under inert and reducing conditions, respectively). This effect, which could be also expected for the physical mixture, is not observed (same profile with and without $\mathrm{H}_{2}$ ) because of the preferential adsorption of this molecule on $\mathrm{Cu}$ nanoparticles, masking the effect of $\mathrm{OH}$ sites of the Mg-Al. This negligible influence of hydrogen is also observed with the $\mathrm{Cu} / \mathrm{Mg}-\mathrm{Al}$, in good agreement with the previous justification. In addition, the lower strong acid sites concentration justifies the low dehydration selectivities obtained with this material.

The competitive adsorption on the acid sites promoted by $\mathrm{OH}$ groups is also noticed analyzing the evolution of 1,3-butadiene, only observing effects due to the hydrogen presence for Mg-Al. However, in this case, the physical mixture seems to be more selective to this compound than the parent $\mathrm{Mg}-\mathrm{Al}$, in contrast to what is happening with ethylene. The analysis of these profiles is not so evident, considering that

Table 1. Characterization results of the mixed oxides: Morphological properties, and density and distribution of the basic and acid sites. Temperatures in brackets corresponds to each maximum of the TPD profiles. *Values reported in a previous work. ${ }^{[17]}$

\begin{tabular}{|c|c|c|c|c|c|c|c|c|c|}
\hline & \multicolumn{3}{|c|}{ Morphological properties } & \multicolumn{3}{|c|}{ Basic sites $\left(\mu \mathrm{mol} \cdot \mathrm{g}^{-1}\right),[\mathrm{T}(\mathrm{K})]$} & \multicolumn{3}{|c|}{ Acid sites $\left(\mu \mathrm{mol} \cdot \mathrm{g}^{-1}\right),[\mathrm{T}(\mathrm{K})]$} \\
\hline & $\begin{array}{c}\mathrm{S}_{\mathrm{BET}} \\
\left(\mathrm{m}^{2} \cdot \mathrm{g}^{-1}\right)\end{array}$ & $\begin{array}{c}V_{p} \\
\left(\mathrm{~cm}^{3} \cdot \mathrm{g}^{-1}\right)\end{array}$ & $\begin{array}{c}D_{p} \\
(n m)\end{array}$ & weak & medium & strong & weak & medium & strong \\
\hline $\mathrm{Mg}-\mathrm{Al}{ }^{*}$ & 226 & 0.7 & 13.5 & $\begin{array}{c}49.7 \\
{[340]}\end{array}$ & $\begin{array}{c}71.7 \\
{[400]}\end{array}$ & $\begin{array}{c}238.6 \\
{[630,670,800]}\end{array}$ & $\begin{array}{c}11.3 \\
{[345,370]}\end{array}$ & $\begin{array}{c}12.5 \\
{[450]}\end{array}$ & $\begin{array}{c}41.8 \\
{[630,800]}\end{array}$ \\
\hline $\mathrm{Cu} / \mathrm{Mg}-\mathrm{Al}$ & 206 & 0.5 & 5.6 & $\begin{array}{c}62.5 \\
{[330,365]}\end{array}$ & $\begin{array}{c}73.1 \\
{[455]}\end{array}$ & $\begin{array}{c}62.5 \\
{[660,715]}\end{array}$ & $\begin{array}{c}4.4 \\
{[330,375]}\end{array}$ & $\begin{array}{c}2.1 \\
{[450]}\end{array}$ & $\begin{array}{c}3.1 \\
{[545]}\end{array}$ \\
\hline $\mathrm{Cu} / \mathrm{SiO}_{2}$ & 160 & 1.2 & 27.3 & - & - & - & - & - & - \\
\hline
\end{tabular}


1,3-butadiene is a C4 compound, being its selectivity not only conditioned by the corresponding active sites but also by the activity in the previous steps, required to obtain the

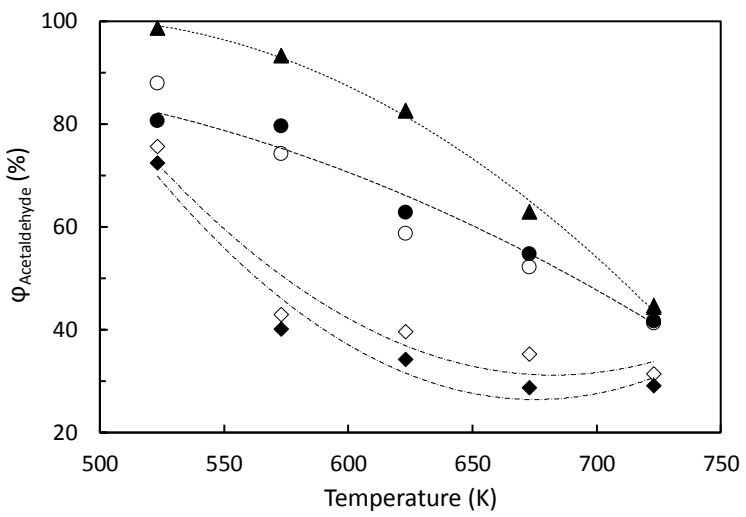

Figure 3. Acetaldehyde selectivity evolution with the temperature under reducing and inert conditions using: $\mathrm{Mg}-\mathrm{Al}{ }^{\star}(\bullet), \mathrm{Cu} / \mathrm{Mg}-\mathrm{Al}(\bullet)$, and $\mathrm{Cu} / \mathrm{SiO}_{2}+\mathrm{Mg}-\mathrm{Al}(\mathbf{\Lambda})$. Black symbols: reducing conditions $\left(20 \mathrm{NmL} \cdot \mathrm{min}^{-1} 10 \mathrm{vol}\right.$ \% $\left.\% \mathrm{H}_{2} / \mathrm{He}\right)$; white symbols: inert conditions $\left(20 \mathrm{NmL} \cdot \mathrm{h}^{-1}\right.$ of $\left.\mathrm{He}\right)$. ${ }^{*}$ Values under inert conditions are obtained from reference [17].

\section{acetaldehyde that promotes the aldol condensation.}

The evolution of acetaldehyde selectivity with the reaction temperature is presented in Figure 3. The clear profile of a primary reaction product undergoing further reaction is observed decreasing the selectivity with the temperature. The same behavior is observed with the three catalytic systems, suggesting that same mechanism (Guerbert reaction) prevails in all the cases. Despite the analyzed temperature, the highest acetaldehyde selectivity is obtained with the physical mixture (improvements up to $141.7 \%$ comparing the $\mathrm{Mg}-\mathrm{Al}$ ) because of the $\mathrm{Cu} / \mathrm{SiO}_{2}$ dehydrogenating functionality. Therefore, there is much more acetaldehyde in the reaction medium when working with the physical mixture, with same values under inert or reducing conditions. The formation of crotonaldehyde directly depends on the acetaldehyde available because of: (i) the aldolization is an acetaldehyde bimolecular non-equilibrated step, ${ }^{[8]}$ and (ii) the concentration and distribution of the active sites that favors this step are the same with both materials. 1,3-butadiene is obtained from crotyl alcohol (as a side product after the first hydrogenation of crotonaldehyde), so the highest amount of acetaldehyde is directly related to the highest 1,3-butadiene selectivity observed for the physical mixture.

It must be also considered that crotyl alcohol is not only the precursor of 1,3-butadiene, but also of 1-butanol. For instance, the 1-butanol/1,3-butadiene selectivity ratio when working under reducing atmosphere is 4.3 at $673 \mathrm{~K}$ with the physical mixture whereas it is 21.9 with the bare Mg-Al. This increase of the selectivity to 1,3-butadiene against 1-butanol when using the physical mixture might be related to a lower amount of hydrogen adatoms on the surface of the acid-basic component of the mixture (Mg-Al) where the unsaturated intermediates are adsorbed. This idea would be justified considering that an important part of the acetaldehyde molecules generated on the $\mathrm{Cu} / \mathrm{SiO}_{2}$ particles are desorbed to the reaction medium and then adsorbed on the $\mathrm{Mg}$-Al component where the aldol condensation is carried out. Consequently, the quantity of hydrogen adatoms on the $\mathrm{Mg}-\mathrm{Al}$ is lower with the physical mixture inasmuch as significant part of the ethanol dehydrogenation is not performed on the Mg-Al component. Thus, although the reduction of the crotonaldehyde to crotyl alcohol can be accomplished by the MPV reaction, the hydrogenation ability of the $\mathrm{C}=\mathrm{C}$ bond of the crotyl alcohol to form 1-butanol (performed by hydrogen adatoms) is lower than that observed with the parent $\mathrm{Mg}-\mathrm{Al}$.

Considering that hydrogenations are the last steps, they are conditioned by the activity in the previous ones, and a deeper analysis of this stage require relative analyses considering the compounds involved by lumped families. Thus, the analysis of the evolution of the selectivity ratio between the sum of all the compounds obtained from crotonaldehyde hydrogenation and further reactions (C4 hydrogenated: crotyl alcohol, butanal, 1,3-butadiene, and 1-butanol) and the sum of the compounds formed from the aldolization step (C4 aldolization: crotonaldehyde + C4 hydrogenated), is depicted in Figure 4. This figure shows that the hydrogenation ability of the physical mixture is lower than that achieved with the parent Mg-Al. Furthermore, it confirms that the presence of molecular hydrogen does not have any effect on the hydrogenation, except when working with the bifunctional catalyst.

The difference in dehydrogenation and hydrogenation capabilities of these catalytic-systems is much clearly observed when the same selectivity ratio is plotted versus the acetaldehyde selectivity, as it is observed in Figure 5. Whereas values corresponding to the bare $\mathrm{Mg}$-Al demonstrate higher hydrogenation ability with regard to dehydrogenation, the physical mixture exhibits the opposite behavior. By contrast, the bifunctional system seems to gather both functionalities, especially in presence of molecular hydrogen, combining large acetaldehyde selectivities with high hydrogenation activities.

Another enhancement directly related to the prevalence of hydrogenation steps is the hindrance of undesired oligomerization processes. In order to check this hypothesis, the evolution of carbon balance closure is plotted in Figure 6a Carbon balance closure is over $75 \%$ with the three materials at all the considered temperatures. In general, higher conversion (Figure 6b) implies lower carbon balance closure, because non-identified compounds (oligomers, not considered for the calculations) tend to be formed. At this point, it must be highlighted that all the compounds depicted in the Scheme $\mathbf{1}$ are perfectly quantified, being the yields of the minor ones included in the Supporting Information (Table S1). Comparing among the three catalysts, carbon balances are higher for the $\mathrm{Cu} / \mathrm{Mg}-\mathrm{Al}$ especially at low temperatures, despite being the conversion

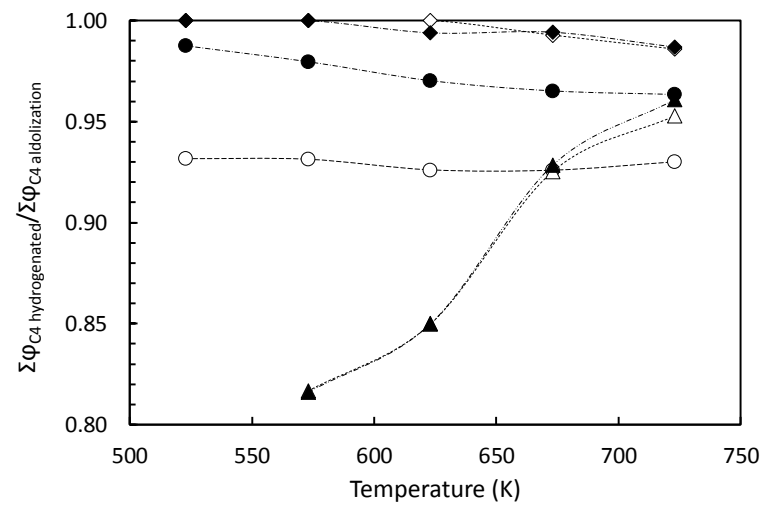

Figure 4. Analysis of the evolution of the hydrogenated C4-aldolization $\mathrm{C} 4$ selectivity ratio with the temperature under presence and absence of hydrogen using: $\mathrm{Mg}^{-\mathrm{Al}}{ }^{*}(\diamond), \mathrm{Cu} / \mathrm{Mg}-\mathrm{Al}$ $(\bullet)$, and $\mathrm{Cu} / \mathrm{SiO}_{2}+\mathrm{Mg}-\mathrm{Al}(\boldsymbol{\Delta})$. Black symbols: reducing conditions (20 NmL min $^{-1} 10$ vol. \% $\mathrm{H}_{2} / \mathrm{He}$ ); white symbols: inert conditions $\left(20 \mathrm{NmL} \cdot \mathrm{h}^{-1}\right.$ of $\left.\mathrm{He}\right) .{ }^{*}$ Values under inert conditions are obtained from reference [17]. 


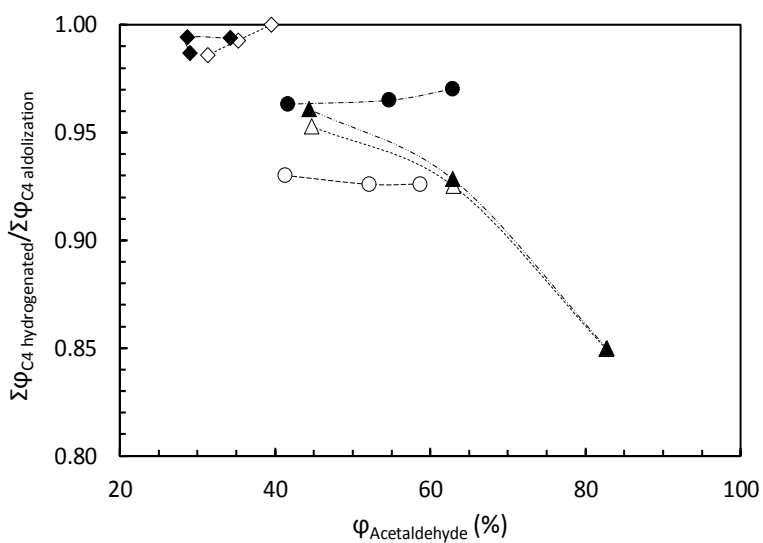

Figure 5. Analysis of the evolution of the hydrogenated C4-aldolization C4 selectivity ratio versus the acetaldehyde selectivity under presence or absence of hydrogen using: $\mathrm{Mg}-\mathrm{Al}{ }^{*}(\bullet), \mathrm{Cu} / \mathrm{Mg}-\mathrm{Al}(\bullet)$, and $\mathrm{Cu} / \mathrm{SiO}_{2}$ $+\mathrm{Mg}-\mathrm{Al}(\boldsymbol{\Delta})$. Black symbols: reducing conditions $\left(20 \mathrm{NmL} \cdot \mathrm{min}^{-1}\right.$ 10 vol. $\left.\% \mathrm{H}_{2} / \mathrm{He}\right)$; white symbols: inert conditions $\left(\mathrm{NmL} \cdot \mathrm{h}^{-1}\right.$ of $\left.\mathrm{He}\right)$. *Values under inert conditions are obtained from reference [17].

lower with the other two materials. This is due to the much higher selectivity towards the main route (1-butanol yield) observed when using the bifunctional material. Regarding the $\mathrm{Mg}-\mathrm{Al}$ and the physical mixture, conversions are lower with the Mg-Al mainly at mild conditions $(11.8$ and $20.5 \%$ at $523 \mathrm{~K}$ with the Mg-Al and the physical mixture, respectively, under reducing conditions) because of the enhancement of the ethanol dehydrogenation with the physical mixture because of the copper presence.

In order to stress the role of copper in the ethanol gas-phase condensation, experiments were carried out using only the $\mathrm{Cu} / \mathrm{SiO}_{2}$ material and comparing the data obtained with the previous results with the bifunctional one. This analysis is only possible if copper crystallite size distribution is similar, since this parameter significantly affects its behavior in these reaction systems. ${ }^{[2]}$ Figure 7 shows the particle size distribution and TPR results of both $\mathrm{Cu} / \mathrm{Mg}-\mathrm{Al}$ and $\mathrm{Cu} / \mathrm{SiO}_{2}$ (HRTEM representative micrographs are included in the Supporting Information, Figure S1). Taking into account that similar copper particle size were obtained with both materials $(1.4$ and $1.9 \mathrm{~nm}$ for the $\mathrm{Cu} / \mathrm{Mg}-\mathrm{Al}$ and $\mathrm{Cu} / \mathrm{SiO}_{2}$, respectively), the conclusions drawn from the functionality of copper when using $\mathrm{Cu} / \mathrm{SiO}_{2}$ can be extrapolated to the $\mathrm{Cu} / \mathrm{Mg}-\mathrm{Al}$ ones.

Preliminary studies were done using the $\mathrm{SiO}_{2}$ support as catalyst (without any metal), confirming the absence of reaction even at the highest temperature tested in this work $(723 \mathrm{~K})$. As the most expected influence of copper nanoparticles is in the dehydrogenation step, Figure 8 summarizes the main results in terms of conversion, carbon balance as well as the acetaldehyde yield. In parallel to the previous analyses, reactions were carried out under reducing and inert atmosphere. Two trends are identified when conversion is analyzed, both under inert and reducing conditions: (i) at mild conditions, temperature has the typical positive effect, increasing conversion at increasing temperatures (from $46.3 \%$ at $523 \mathrm{~K}$ to $77.1 \%$ at $573 \mathrm{~K}$ under inert conditions; and from $41.3 \%$ to $70.3 \%$ under reducing atmosphere, at similar conditions); (ii) this trend is broken at high temperatures, with a clear decreasing tendency (reaching values around $40 \%$ at $723 \mathrm{~K}$ ), for both atmospheres. This fact suggests an undesired phenomenon that partially deactivates the material at these more severe conditions. One of the possible reasons of this

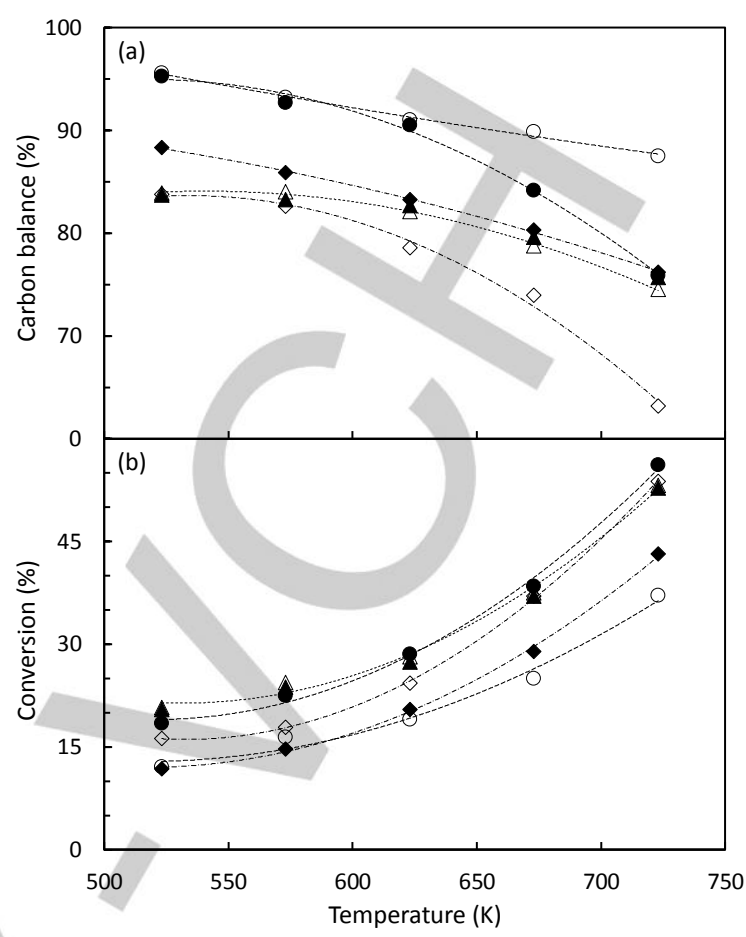

Figure 6. Evolution of: (a) carbon balance closure and (b) conversion, with the temperature under reducing and inert conditions using: $\mathrm{Mg}-\mathrm{Al}{ }^{*}$ $(\bullet), \mathrm{Cu} / \mathrm{Mg}-\mathrm{Al}(\bullet)$, and $\mathrm{Cu} / \mathrm{SiO}_{2}+\mathrm{Mg}-\mathrm{Al}(\boldsymbol{\Delta})$. Black symbols: reducing conditions $\left(20 \mathrm{NmL} \cdot \mathrm{min}^{-1} 10 \mathrm{vol} . \% \mathrm{H}_{2} / \mathrm{He}\right)$; white symbols: inert conditions $\left(20 \mathrm{NmL} \cdot \mathrm{h}^{-1}\right.$ of $\left.\mathrm{He}\right)$. ${ }^{*}$ Values under inert conditions are obtained from reference [17].

behavior is the copper nanoparticle sintering (major drawback of copper regarding other metals ${ }^{[23]}$ ).

In order to determine the role of sintering, catalyst samples were recovered after reactions at the highest temperatures tested $(723 \mathrm{~K})$ while working under inert atmosphere (the most favorable conditions for crystallite agglomeration). Analyses by HRTEM showed that the copper clusters supported on the silica sintered, evolving from 1.9 to $4.1 \mathrm{~nm}$ of mean size. However, this phenomenon was not observed for the spent $\mathrm{Cu} / \mathrm{Mg}-\mathrm{Al}$ catalyst, keeping the size of the copper particles in the same value (HRTEM representative micrographs and particle size histograms of spent $\mathrm{Cu} / \mathrm{Mg}-\mathrm{Al}$ and $\mathrm{Cu} / \mathrm{SiO}_{2}$ are included in Figure S2 and S3). This fact suggests that the interaction between the support and the metal nanoparticles is stronger with $\mathrm{Mg}$-Al support than with $\mathrm{SiO}_{2 .}{ }^{[12]}$ Indeed, TPR results (Figure 7c) confirm this idea, since the reduction temperature when using $\mathrm{Mg}-\mathrm{Al}$ as support is much higher than with $\mathrm{SiO}_{2}$. (688 K with $\mathrm{Mg}-\mathrm{Al}$, and in the range of $390-430 \mathrm{~K}$ with $\mathrm{SiO}_{2}$ ). These values are in agreement to those previously reported when using a similar mixed oxide $(\mathrm{Zr}-\mathrm{Al})$ and $\mathrm{SiO}_{2} \cdot{ }^{[24,25]}$ Furthermore, the particle size histogram of the fresh $\mathrm{Cu} / \mathrm{SiO}_{2}$ shows a bimodal distribution that is supported by the TPR results (Figure $7 \mathrm{~b}$ and c) since two distinguishable peaks, related to two types of clusters different in size (CuO precursors), appear within the temperature reduction range. This fact favors the particle growth: catalysts with more heterogeneous crystallite size distribution are more prone to sintering. ${ }^{[26]}$ Anyway, the increase of the copper cluster mean diameter is not too significant, since they are kept within low size $(<10 \mathrm{~nm})$. Therefore, the sintering observed for the $\mathrm{Cu} / \mathrm{SiO}_{2}$ seems to be not the only deactivation cause. 

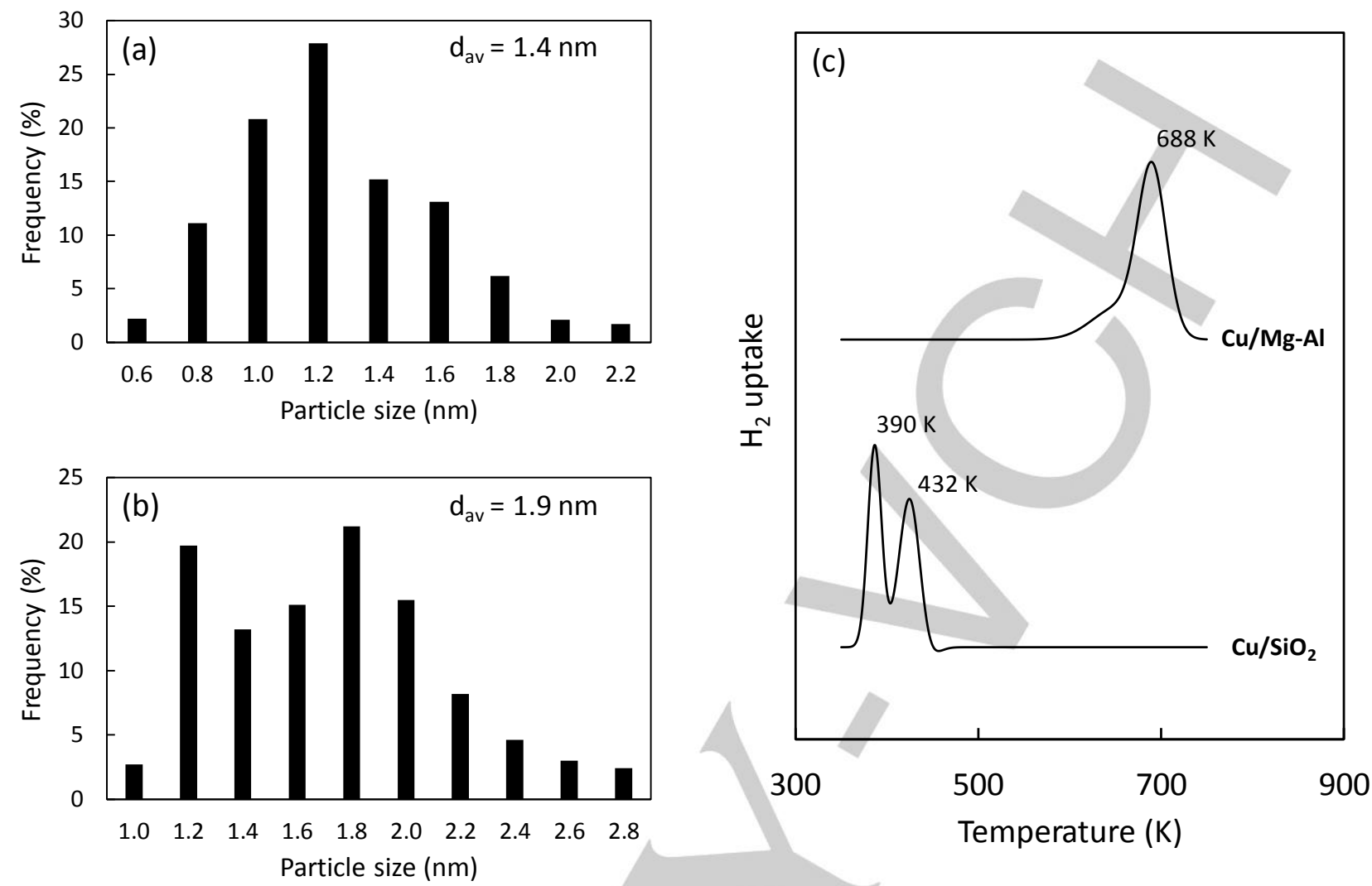

Figure 7. Particle size distribution determined by HRTEM: (a) Cu/Mg-Al, and (b) $\mathrm{Cu} / \mathrm{SiO}_{2}$. (c) $\mathrm{TPR}$ results for the $\mathrm{Cu} / \mathrm{Mg}-\mathrm{Al}$, and $\mathrm{Cu} / \mathrm{SiO}_{2}$.

Under reducing atmosphere, the maximum conversion matches with the minimum carbon balance (79.3\%) (Figure 8), which suggests that adsorption processes affect catalyst performance. C4 molecules (crotonaldehyde, crotyl alcohol, butanal, 1-butanol, and ethyl acetate) are identified during the reaction, being the ethyl acetate (yield up to $0.5 \%$ at $573 \mathrm{~K}$ working under inert conditions) the main one. The activity of copper nanoparticles for aldolization and esterification reactions was previously observed, ${ }^{[2]}$ justifying this appearance despite the catalyst has not acid/basic sites. In addition to the $\mathrm{C} 4$

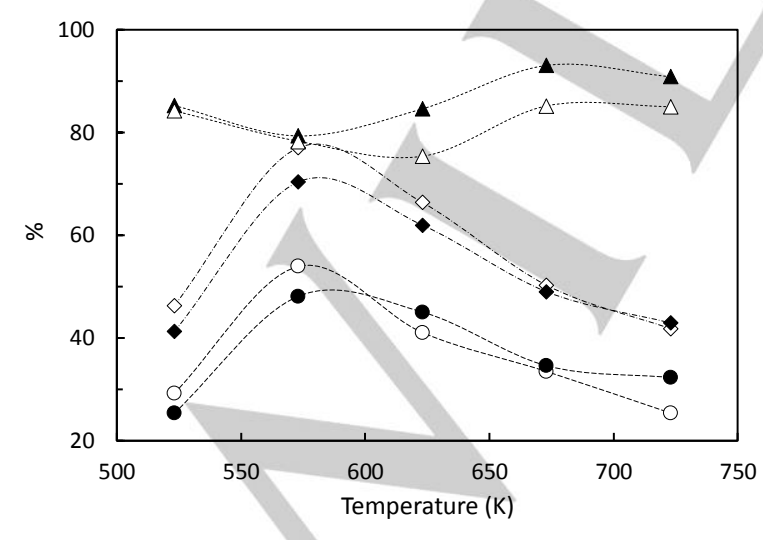

Figure 8. Conversion $(\bullet)$, carbon balance closure $(\mathbf{A})$, and acetaldehyde yield $(\bullet)$ evolution in the ethanol gas phase condensation on $\mathrm{Cu} / \mathrm{SiO}_{2}(0.15 \mathrm{~g})$. Black symbols: reducing conditions $\left(20 \mathrm{NmL} \cdot \mathrm{min}^{-1}\right.$ of $\left.10 \mathrm{vol} \% \mathrm{H}_{2} / \mathrm{He}\right)$; white symbols: inert conditions $\left(20 \mathrm{NmL} \cdot \mathrm{h}^{-1}\right.$ of $\left.\mathrm{He}\right)$. compounds, methane and carbon monoxide were detected, indicating that acetaldehyde decarbonylation (maximum selectivity to methane of $3.4 \%$ at $723 \mathrm{~K}$ under inert conditions) is taking place. Decarbonylation reaction is less relevant in the presence of copper nanoparticles regarding other metals (such as iridium, ruthenium, and platinum) ${ }^{[27]}$ but the extent of this reaction is directly related to the acetaldehyde concentration. Carbon monoxide is stoichiometrically formed at the same extent as methane, but the amount observed is only around $85 \%$ of the methane one, suggesting a strong adsorption on the metallic phase, implying its partial deactivation. ${ }^{[28]}$ As a consequence, the ethanol conversion continuously decreases as temperature increases when the bimolecular and decarbonylation reactions become more important. Nevertheless, although the acetaldehyde yield decreases with the temperature (from $53.9 \%$ at $573 \mathrm{~K}$ to $25.3 \%$ at $723 \mathrm{~K}$ under inert conditions; and from $48.1 \%$ to $32.2 \%$ under reducing atmosphere, at similar conditions), its relative weight in the global amount of detected products (those shown in Scheme 1) is always higher than 95.4 and $94.6 \%(723 \mathrm{~K})$ in presence and absence of hydrogen, respectively. These values correspond to selectivities of 60.7 and $75.1 \%$, respectively. Furthermore, the water gas shift reaction could be taking place, allowing the formation of carbon dioxide due to the water presence in the reaction medium (produced from the aldol condensation step, and dehydration side-reactions)

The whole analysis of all these data requires the study of the evolution of species adsorbed on the catalytic surfaces. DRIFT spectra when working with the $\mathrm{Cu} / \mathrm{SiO}_{2}$ material is shown in Figure 9. Bands at wavenumbers of: 1050, 1220, 2880, 2940, and $2970 \mathrm{~cm}^{-1}$ related to the vibrations modes: CO stretching, $\mathrm{C}-\mathrm{O}$ stretching, and $\mathrm{CH}_{3}$ and $\mathrm{CH}_{2}$ stretching arise at all the 


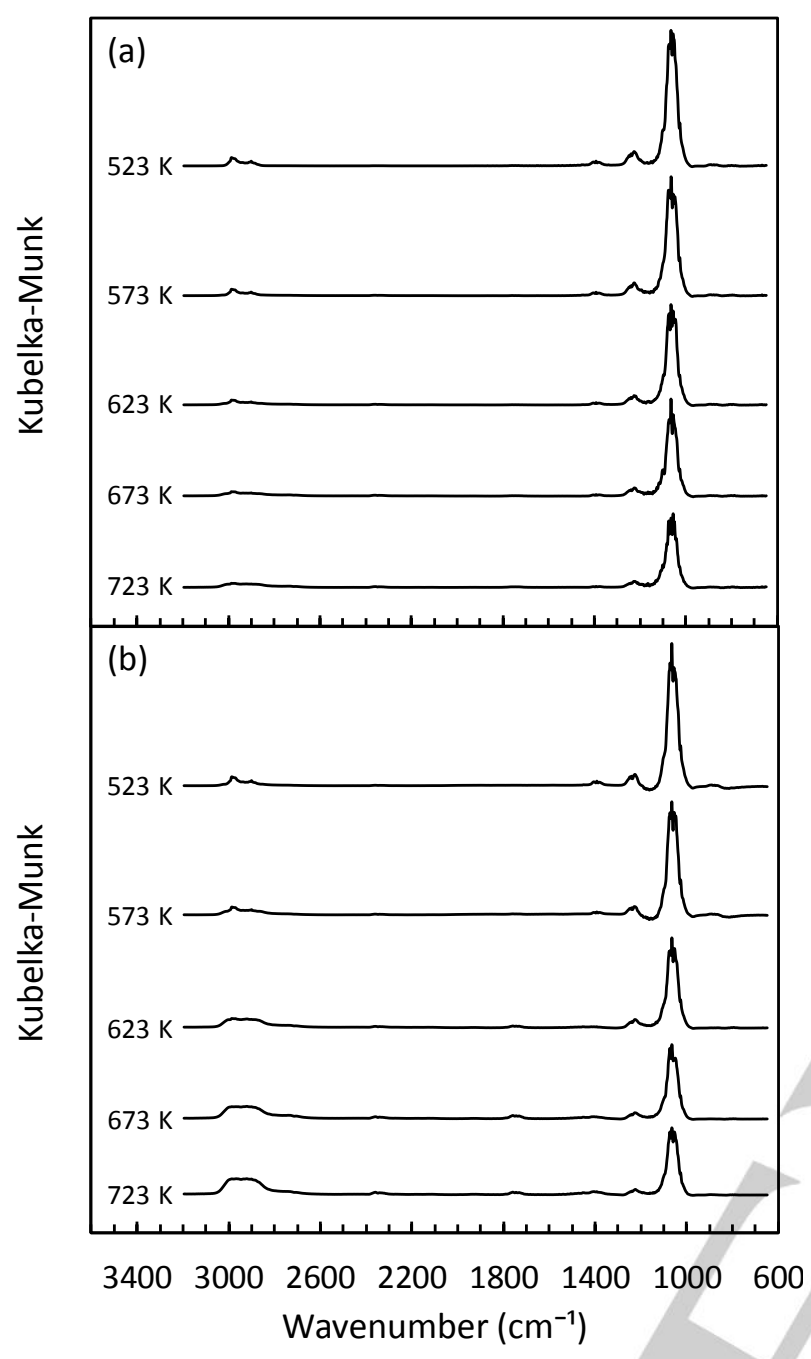

Figure 9. DRIFT spectra in the ethanol gas-phase condensation on $\mathrm{Cu} / \mathrm{SiO}_{2}$ under (a) reducing and (b) inert conditions.

tested temperatures. ${ }^{[17]}$ These bands are associated with the ethanol adsorption. Furthermore, a band at $1380 \mathrm{~cm}^{-1}(\mathrm{C}-\mathrm{H}$ bending vibration mode) related to acetaldehyde is observed at the lowest temperatures. ${ }^{[17]}$ This last band almost disappears at the highest temperature because of the decrease of the acetaldehyde formation and the exothermic nature of the adsorption phenomenon. Because of this, the intensity of some of the adsorption bands mentioned above decreases. However, when the spectra collected under reducing and inert conditions are compared (Figure 9a and b, respectively), relevant differences at temperatures above $623 \mathrm{~K}$ can be noticed: (i) a band at $1740 \mathrm{~cm}^{-1}(\mathrm{C}=\mathrm{O}$ stretching vibration mode) associated with higher aldehydes $(\geq \mathrm{C} 4)$ arises under inert conditions:; ${ }^{[17]}$ (ii) the band related to $\mathrm{CH}_{3}$ and $\mathrm{CH}_{2}$ stretching vibration modes begins growing, suggesting the formation and adsorption of higher species ( $\geq$ C4) under inert conditions. These two differences are directly related to the hydrogen feeding; when hydrogen is supplied these species formed under inert conditions are more easily reduced and desorbed. Furthermore, the presence of hydrogen also inhibits the decarbonylation of acetaldehyde (methane selectivity of 2.4 and $3.4 \%$ at $723 \mathrm{~K}$ under reducing and inert conditions, respectively). Consequently, the conversions are very similar above $623 \mathrm{~K}$, under reducing or inert conditions (i.e., 41.7 and $42.9 \%$ at $723 \mathrm{~K}$ under inert and reducing conditions, respectively). This is not observed for the acetaldehyde yield, comparing with the two lowest temperatures at which the ethanol dehydrogenation prevails over all the reactions. Anyway, the role of the hydrogen feeding on the performance of the inverse dehydrogenation (acetaldehyde hydrogenation to ethanol) is very low since conversions are very similar at the lowest temperatures (main difference observed at $573 \mathrm{~K}$ : conversion $6.8 \%$ higher working under inert conditions). Moreover, as temperature increases, the reaction extent approaches the ethanol-acetaldehyde equilibrium. Thus, at $573 \mathrm{~K}$, the reaction quotient $(\mathrm{Q})$, calculated with the experimental data, is around the 70 and $85 \%$ of the theoretical equilibrium constant $(\mathrm{K})$ in presence and absence of hydrogen, respectively. Nevertheless, the highest approaches to ethanol-acetaldehyde equilibrium $(\mathrm{Q} / \mathrm{K})$ when working with the $\mathrm{Cu} / \mathrm{Mg}-\mathrm{Al}$ are 3 and $14 \%$ under inert and reducing conditions reached at the lowest temperature tested. In this light, copper nanoparticles are considered as a co-catalyst which favors the dehydrogenation of ethanol and the activation of the hydrogen molecule, and therefore the main step (aldolization) is only attributed to the acid-basic material (Mg-Al surface in the $\mathrm{Cu} / \mathrm{Mg}-\mathrm{Al}$ catalyst, and $\mathrm{Mg}-\mathrm{Al}$ component in the physical mixture). This conclusion supports the good analysis of the physical mixture, only considering the Mg-Al component in the 1-butanol productivity calculations. 
DRIFT spectra evolution with the temperature when using the $\mathrm{Cu} / \mathrm{Mg}-\mathrm{Al}$ are shown in Figure 10. In addition to the above mentioned bands, two new bands can be distinguished at 1660 and $3030 \mathrm{~cm}^{-1}$, corresponding to $\mathrm{C}=\mathrm{C}$ (related to crotonaldehyde and crotyl alcohol) and C-H stretching modes (associated with aldehydes). ${ }^{[17]}$ The significance of the bands linked to higher unsaturated species $(1660,1740$, and the band around $3000 \mathrm{~cm}^{-1}$, related to $\mathrm{C}=\mathrm{C}, \mathrm{C}=\mathrm{O}$, and $\mathrm{CH}_{3}, \mathrm{CH}_{2}$ and $\mathrm{CH}$ stretching vibrations modes) is lower regarding to the previous results reported when using $\mathrm{Mg}-\mathrm{Al} .^{[17]}$ This is consistent with the lower concentration of acid sites on the $\mathrm{Cu} / \mathrm{Mg}-\mathrm{Al}$ (Table 1) being those sites that favor the stabilization of the intermediate species on the catalytic surface. There are almost no differences between the spectra at each temperature when reducing and inert conditions are compared (Figure 10a and b), with only slight differences in the intensity of the band related to the $\mathrm{CO}$ stretching vibration mode $\left(1050 \mathrm{~cm}^{-1}\right)$.

As a summary of all these studies, results for the 1-butanol productivity, conversion, carbon balance closure, and selectivities to the main compounds obtained under inert conditions are different from that observed when working in presence of hydrogen. Nevertheless, concerning the physical mixture, all these evolutions are almost the same as those

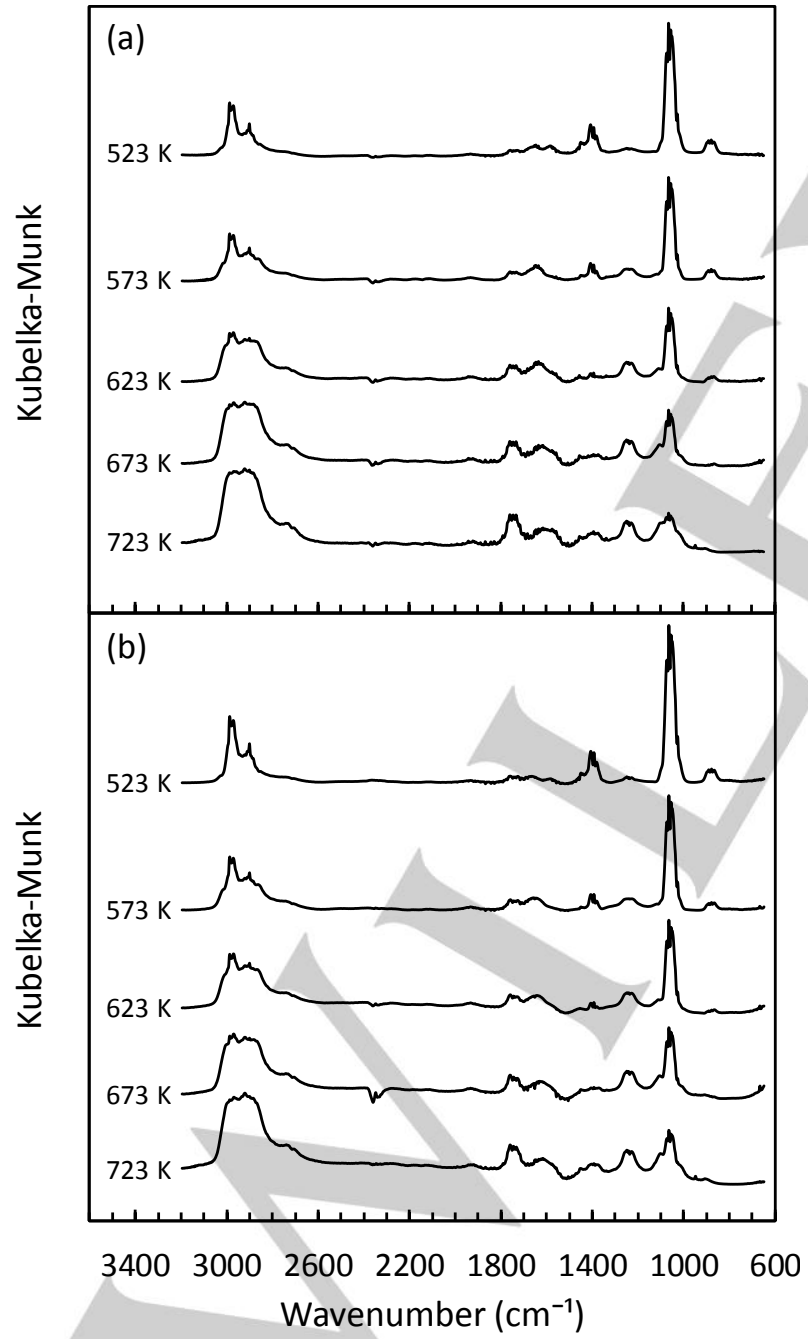

Figure 10. DRIFT spectra in the ethanol gas-phase condensation on $\mathrm{Cu} / \mathrm{Mg}-\mathrm{Al}$ under (a) reducing and (b) inert conditions. obtained under reducing atmosphere, as it was expected. In view of this and the DRIFT spectra, it is as if in the case of the bifunctional catalyst the hydrogen presence raised the turnover frequency of the active sites, but the species formed on the catalytic surface were the same as those generated under inert atmosphere (the degree of the surface saturation by the formed species is similar).

\section{Conclusions}

The production of 1-butanol in the ethanol gas phase condensation over Mg-Al mixed oxide is enhanced by supporting copper nanoparticles, the improvement being especially significant at mild temperatures (523 and $573 \mathrm{~K}$ ). Thus, this procedure is a very promising way to produce 1-butanol at softer conditions than the normally required. A relevant improvement in the 1-butanol productivity is achieved with only $1 \mathrm{wt}$. \% of copper loading on the Mg-Al material regarding to the bare $\mathrm{Mg}-\mathrm{Al}$ (12 times higher with the $\mathrm{Cu} / \mathrm{Mg}-\mathrm{Al}$ regarding to the bare $\mathrm{Mg}-\mathrm{Al}$ at $523 \mathrm{~K}$ ). This enhancement is due to the dehydrogenation ability of copper, which promotes the first step of the ethanol Guerbet reaction (acetaldehyde formation). Furthermore, when hydrogen is supplied to the reaction medium, the 1 -butanol productivity improvement is even higher than under inert conditions when working with the $\mathrm{Cu} / \mathrm{Mg}-\mathrm{Al}$ catalyst because of the activation of the hydrogen molecule by copper (enhancement of $150 \%$ comparing inert and reducing conditions at $523 \mathrm{~K}$ ). A good distribution and vicinity of the active sites involved in the different steps (mainly metal active and acid-basic sites) is considered as the key reason for the 1-butanol productivity enhancement. This conclusion is drawn by: (i) comparing in reaction under both reducing and inert conditions the bifunctional material $(\mathrm{Cu} / \mathrm{Mg}-\mathrm{Al})$ with a physical mixture $\left(\mathrm{Cu} / \mathrm{SiO}_{2}+\mathrm{MgAl}\right)$; (ii) observing the acid-base properties that are very similar to favor the key aldolization step (similar acid-base pairs distribution and concentration between $\mathrm{Cu} / \mathrm{Mg}-\mathrm{Al}$ and $\mathrm{Mg}-\mathrm{Al}$ ). DRIFT spectroscopy shows that the species formed during the reaction are the same regardless of the material used ( $\mathrm{Mg}-\mathrm{Al}$ or $\mathrm{Cu} / \mathrm{Mg}-\mathrm{Al}$ ) and the conditions (reducing or inert), suggesting that the improvement in the 1-butanol productivity is only related to an increase of the turnover frequency of the different active sites.

\section{Experimental Section}

\section{Materials Synthesis}

$\mathrm{Mg}-\mathrm{Al}$ mixed oxide $(\mathrm{Mg} / \mathrm{Al}=3)$ was synthesized following the procedure detailed in a previous work. ${ }^{[16]}$ The $1 \mathrm{wt}$ \% Cu/Mg-Al catalyst was prepared by incipient wetness impregnation of copper (II) nitrate hydrate (Panreac) on the Mg-Al mixed oxide used as support. The resulting material was dried in an oven at $383 \mathrm{~K}$ for $24 \mathrm{~h}$. Hereafter, it was treated in flowing air from room temperature (ca. $293 \mathrm{~K}$ ) to $973 \mathrm{~K}$ with a step of $5 \mathrm{~K} \cdot \mathrm{min}^{-1}$, holding 5 hours the final temperature. Then, the $\mathrm{Cu}$ was reduced treating the calcined material under a mixture of $10 \mathrm{vol} . \% \mathrm{H}_{2} / \mathrm{Ar}$ (20 NmL. $\mathrm{min}^{-1}$ ) from room temperature (ca. $293 \mathrm{~K}$ ) to $673 \mathrm{~K}$, holding this temperature for $3 \mathrm{~h}$. The reduction temperature was selected according to the results obtained during the characterization of the calcined precursor. The $1 \mathrm{wt}$ \% $\mathrm{Cu} / \mathrm{SiO}_{2}$ catalyst was prepared under the same procedure followed as in the $\mathrm{Cu} / \mathrm{Mg}$-Al preparation using inert silica (fumed $\mathrm{SiO}_{2}$, Aldrich) as support. Furthermore, a mechanical mixture of $\mathrm{Cu} / \mathrm{SiO}_{2}: \mathrm{Mg}-\mathrm{Al}$ (1:1) was prepared by milling and pelletizing the same amounts of $\mathrm{Cu} / \mathrm{SiO}_{2}$ and $\mathrm{Mg}-\mathrm{Al}$ mixed oxide. 


\section{Catalytsts' characterization}

Temperature-programmed reduction (TPR) experiments were performed in a Micromeritics AutoChem II 2920 followed by a Pfeiffer Vacuum Omnistar Prisma mass spectrometer, in order to determine the catalysts precursors reduction-temperature. The calcined materials $(20 \mathrm{mg})$ were exposed under $10 \mathrm{vol} . \% \mathrm{H}_{2} / \mathrm{Ar}$ flow $\left(20 \mathrm{NmL} \cdot \mathrm{min}^{-1}\right)$ from room temperature (ca. $293 \mathrm{~K}$ ) to $973 \mathrm{~K}$ with temperature rate of $5 \mathrm{~K} \cdot \mathrm{min}^{-1}$. The textural properties of the reduced catalysts were analyzed by $\mathrm{N}_{2}$ physisorption at $77 \mathrm{~K}$, using a Micromeritics ASAP 2020 to measure the surface area, pore volume and diameter. Surface basicity and acidity were determined by temperature programmed desorption (TPD) with a Micromeritics 2900 TPD/TPR equipment. Samples of both materials $(20 \mathrm{mg})$ were pretreated under flowing $\mathrm{He}\left(20 \mathrm{NmL} \cdot \mathrm{min}^{-1}\right)$ at $393 \mathrm{~K}$, and saturated with $\mathrm{CO}_{2}\left(5 \mathrm{NmL} \cdot \mathrm{min}^{-1}\right)$ or $\mathrm{NH}_{3}\left(20 \mathrm{NmL} \cdot \mathrm{min}^{-1}\right.$ of 2.5 vol\% $\mathrm{NH}_{3} / \mathrm{He}$ mixture) during $15 \mathrm{~min}$. to analyze the basicity or acidity, respectively. The $\mathrm{CO}_{2}$ and $\mathrm{NH}_{3}$ signals evolution were monitored by mass spectrometry (Pfeiffer Vacuum Omnistar Prisma) while increasing the temperature from 298 to $973 \mathrm{~K}$ with a temperature ramp of $2.5 \mathrm{~K} \cdot \mathrm{min}^{-1}$. High-resolution transmission electron microscopy (HRTEM) analyses of samples of both materials were performed to determine the particle size distribution (counting a number of particles, $n$, higher than one hundred), using a JEOL JEM-2100 equipment. The mean particle size $\left(\mathrm{d}_{\mathrm{av}}\right)$ is calculated by the following formula: $\mathrm{d}_{\mathrm{av}}=$ $\sum_{\mathrm{i}} \mathrm{n}_{\mathrm{i}} \mathrm{d}_{\mathrm{i}}^{3} / \sum_{\mathrm{i}} \mathrm{n}_{\mathrm{i}} \mathrm{d}_{\mathrm{i}}^{2}$, where $\mathrm{d}$ is the size of a specific particle. ${ }^{[29]}$

\section{Catalytic activity studies}

Experiments were carried out between 523 and $723 \mathrm{~K}$ spacing $50 \mathrm{~K}$ in a $0.4 \mathrm{~cm}$ i.d. U-shaped fixed-bed quartz reactor placed in an electric furnace PID controlled. The catalyst sample was held by a quartz wool plug, as well as the temperature was measured with a thermocouple placed close to the catalyst bed. Samples of $0.15 \mathrm{~g}$ of $\mathrm{Cu} / \mathrm{SiO}_{2}$ or $\mathrm{Cu} / \mathrm{Mg}-\mathrm{Al}$, and $0.3 \mathrm{~g}$ of the physical mixture (sieved in the range 250-355 $\mu \mathrm{m}$ ) were used in each experiment. These conditions were optimized in a previous paper, discarding any mass transference limitation. ${ }^{[17]}$ Samples were pretreated at $523 \mathrm{~K}$ for $1 \mathrm{~h}$ under flow of $10 \mathrm{vol} . \% \mathrm{H}_{2} / \mathrm{He}$ mixture $\left(20 \mathrm{NmL} \cdot \mathrm{min}^{-1}\right)$ previous all experiments. Absolute ethanol $\left(\geq 99.9 \%\right.$, VWR) was fed to the reactor $\left(1.5 \mathrm{~mL} \cdot \mathrm{h}^{-1}\right)$ injected by a syringe pump in the $10 \mathrm{vol} . \% \mathrm{H}_{2} / \mathrm{He}$ or $\mathrm{He}$ flow $\left(20 \mathrm{NmL} \cdot \mathrm{min}^{-1}\right)$ depending on if the experiment is carried out under reducing or inert conditions. The resulting stream contains a $32 \mathrm{~mol} \%$ of ethanol, being the weight hourly space velocity (WHSV) $8 \mathrm{~h}^{-1}$.

The reactor outgoing effluent was on-line analyzed by gas chromatography, using a flame ionization detector (GC-FID, HP 6890Plus chromatograph). A capillary column (TRB 5MS; $30 \mathrm{~m}$, $0.25 \mathrm{~mm}$ ) was used as stationary phase. In addition, off-line GC-FID analyses (Agilent $6890 \mathrm{~N}$ ) were carried out, working with two different columns (HP-Plot Q, $30 \mathrm{~m}, 0.53 \mathrm{~mm}$; and HP-Plot MoleSieve $5 \mathrm{~A}, 30 \mathrm{~m}, 0.53 \mathrm{~mm}$ ) in order to separate methane (product of acetaldehyde decarbonylation) and ethylene (from ethanol dehydration). These two light hydrocarbons cannot be separated with the GC column installed in the on-line experimental setup. The identification of the different chemical species was carried out using commercial standards in a gas chromatograph equipped with a mass spectrometer detector, GC-MS, (Shimadzu QP-2010) following the same methodology and using a similar column than in the determination of the reaction outlet gases (GC-FID).
Conversions were calculated from the ethanol concentrations at the reactor inlet and outlet streams. Carbon balances were determined checking the total quantity of carbon atoms at the reactor inlet and outlet, only considering the identified compounds (ethanol, acetaldehyde, crotonaldehyde, crotyl alcohol, 1-butanol, ethyl acetate, butanal, ethylene, diethyl ether, methane, and carbon monoxide).

The productivity of each component (i) in the reaction (or average formation rate) were calculated as follows:

$$
\text { productivity of } \mathrm{i}\left(\mathrm{mmol} \cdot \mathrm{ks}^{-1} \cdot \mathrm{g}^{-1}\right)=\frac{\mathrm{F} \cdot \mathrm{x} \cdot \varphi_{\mathrm{i}}}{\mathrm{W}}
$$

$\mathrm{F} \equiv$ molar flow of ethanol supplied to the reactor $\left(\mathrm{mmol} \cdot \mathrm{ks}^{-1}\right)$

$\mathrm{W} \equiv$ mass of catalyst $(\mathrm{g})$

$\mathrm{x} \equiv$ ethanol conversion

$\varphi_{\mathrm{i}} \equiv$ Selectivity for the formation of compound $\mathrm{i}$ in carbon basis (moles of $\mathrm{C}$ of ethanol converted to the component $\mathrm{i} / \mathrm{moles}$ of $\mathrm{C}$ of converted ethanol)

The yield of every product was determined as follows:

Yield $_{\mathrm{i}}(\%)=\left(\frac{\text { Moles of } \mathrm{C} \text { of ethanol converted to product } \mathrm{i}}{\text { Moles of } \mathrm{C} \text { of ethanol fed }}\right) \cdot 100$

Infrared spectra at reaction conditions.

Infrared spectra were acquired by DRIFT spectroscopy with a Thermo Nicolet Nexus FT-IR equipped with a MCT/A detector. The sample of catalyst $(20 \mathrm{mg})$ in each experiment was placed inside the catalytic chamber that allowed control the temperature. The material was pretreated at $523 \mathrm{~K}$ for 1 hour in $10 \mathrm{vol}$. \% $\mathrm{H}_{2} / \mathrm{He}$ flow before the test. Spectra were recorded in the 650$4000 \mathrm{~cm}^{-1}$ wavenumber range, subtracting the $\mathrm{KBr}$ standard background. All signals were converted using the Kubelka-Munk method, obtaining semi-quantitative results that allow comparison between the obtained spectra. Spectra were acquired at all the reaction temperatures tested for the reactor experiments, making possible the comparison of the evolution of the compounds in the gas phase as well as on the catalytic surface.

\section{Acknowledgements}

Authors thank financial support for this work from the Ministry of Economy and Competitiveness of Spain (CTQ2014-52956-C3-1-R; CTQ2017-89443-C3-2-R). Jorge Quesada acknowledges the local Government of the Principality of Asturias for his PhD fellowship of the Severo Ochoa Program (PA-14-PF-BP14-105).

Keywords: aldol reaction $\cdot \mathrm{C}-\mathrm{C}$ coupling $\cdot$ hydrogenation • Guerbert reaction $\cdot 1$-butanol

\section{References}

[1] C. Angelici, B. M. Weckhuysen, P. C. A. Bruijnincx, ChemSusChem 2013, 6, 1595-1614.

[2] M. E. Sad, M. Neurock, E. Iglesia, J. Am. Chem. Soc. 2011, 133, 20384-20398. 
[3] S. Wang, E. Iglesia, J. Phys. Chem. C 2016, 120, 2158921616.

[4] S. Wang, K. Goulas, E. Iglesia, J. Catal. 2016, 340, 302320.

[5] a) J. Sun, Y. Wang, ACS Catal. 2014, 4, 1078-1090; b) L. Faba, E. Díaz, S. Ordóñez, Renew. Sustain. Energy Rev. 2015, 51, 273-287.

[6] a) H. Aitchison, R. L. Wingad, D. F. Wass, ACS Catal. 2016, 6, 7125-7132; b) S. Hanspal, Z. D. Young, H. Shou, R. J. Davis, ACS Catal. 2015, 5, 1737-1746.

[7] J. T. Kozlowski, R. J. Davis, ACS Catal. 2013, 3, 15881600.

[8] T. Moteki, D. W. Flaherty, ACS Catal. 2016, 6, 4170-4183.

[9] a) S. Abelló, F. Medina, D. Tichit, J. Pérez-Ramírez, J. C. Groen, J. E. Sueiras, P. Salagre, Y. Cesteros, Chem.-Eur. J. 2015, 11, 728-739; b) M. J. Climent, A. Corma, V. Fornés, R. Guil-López, S. Iborra, Adv. Synth. Catal. 2002 344, 1090-1096; c) J. I. Di Cosimo, V. K. Díez, C. R. Apesteguía, Appl. Catal. A Gen. 1996, 137, 149-166; d) G. Zhang, H. Hattori, K. Tanabe, Appl. Catal. 1988, 36, 189-197.

[10] W. Dai, L. Ren in Handbook of Heterogeneous Catalysis, 2nd ed., Editors: G. Ertl, H. Knözinger, F. Schüth, J. Weitkamp, Wiley-VCH, Weinheim, 2008, Vol. 7, pp. 32593262.

[11] a) A. G. Sato, D. P. Volanti, I. C. de Freitas, E. Longo, J. M. C. Bueno, Catal. Comm. 2012, 26, 122-126; b) I. C. Freitas, S. Damyanova, D. C. Oliveira, C. M. P. Marques, J. M. C. Bueno, J. Mol. Catal. A Chem. 2014, 381, 26-37.

[12] J. H. Earley, R. A. Bourne, M. J. Watson, M. Poliakoff, Green Chem. 2015, 17, 3018-3025.

[13] D. Jiang, X. Wu, J. Mao, J. Ni, X. Li, Chem. Comm. 2016, 52, 13749-13752.

[14] a) X. Wu, G. Fang, Z. Liang, W. Leng, K. Xu, D. Jiang, J. Ni, X. Li, Catal. Comm. 2017, 100, 15-18; b) J. Pang, M. Zheng, L. He, L. Li, X. Pan, A. Wang, X. Wang, T. Zhang, J. Catal. 2016, 344, 184-193.

[15] J. I. Di Cosimo, C. R. Apesteguía, M. J. L. Ginés, E. Iglesia, J. Catal. 2000, 190, 261-275.

[16] M. León, E. Díaz, S. Ordóñez, Catal. Today 2011, 164, 436-442.

[17] J. Quesada, L. Faba, E. Díaz, S. Ordóñez, Appl. Catal. A Gen. 2017, 542, 271-281.

[18] a) J. I. Di Cosimo, V. K. Díez, M. Xu, E. Iglesia, C. R. Apesteguía, J. Catal. 1998, 178, 499-510; b) S. Ogo, A Onda, K. Yanagisawa, Appl. Catal. A Gen. 2011, 402, 188195; c) J. T. Kozlowski, R. J. Davis, J. Energy Chem. 2013, 22, 58-64; d) L. Silvester, J. F. Lamonier, J. Faye, M. Capron, R. N. Vannier, C. Lamonier, J. L. Dubois, J. L. Couturier, C. Calais, F. Dumeignil, Catal. Sci. Technol. 2015, 5, 2994-3006; e) A. S. Ndou, N. Plint, N. J. Coville, Appl. Catal. A Gen. 2003, 251, 337-345; f) C. Yang, Z. Meng, J. Catal. 1993, 142, 37-44.; g) P. E. Hathaway, M. E. Davis, J. Catal. 1989, 119, 497-507.

[19] G. C. Bond in Metal-Catalysed Reactions of Hydrocarbons, Fundamental and Applied Catalysis Series, Editors: M. V. Twigg, M. S. Spencer, Springer, New York, 2005; pp. 133135.

[20] J. J. Ramos, V. K. Díez, C. A. Ferretti, P. A. Torresi, C. R. Apesteguía, J. I. Di Cosimo, Catal. Today 2011, 172, 141 147.

[21] D. D. Eley, M. A. Zammitt, J. Catal. 1971, 21, 366-376.

[22] M. Boudart, A. Delbouille, E. G. Derouane, V. Indovina, A. B. Walters, J. Am. Chem. Soc. 1972, 94, 6622-6630.

[23] X. Wu, G. Fang, Y. Tong, D. Jiang, Z. Liang, W. Leng, L. Liu, P. Tu, H. Wang, J. Ni, X. Li, ChemSusChem 2018, 11 , 71-85.
[24] G. V. Sagar, P. V. R. Rao, C. S. Srikanth, K. V. R. Chary, J. Phys. Chem. B 2006, 110, 13881-13888.

[25] C. J. G. van der Grift, A. Mulder, J. W. Geus, Appl. Catal. 1990, 60, 181-192.

[26] G. Prieto, J. Zečević, H. Friedrich, K. P. de Jong, P. E. de Jongh, Nat. Mater. 2012, 12, 34-39.

[27] E. I. Gürbüz, D. D. Hibbits, E. Iglesia, J. Am. Chem. Soc. 2015, 137, 11984-11995.

[28] T. Bligaard, J. K. Nørskov, S. Dahl, J. Matthiesen, C. H. Christensen, J. Sehested, J. Catal. 2004, 224, 206-217.

[29] H. Arnold, F. Döbert, J. Gaube in Handbook of Heterogeneous Catalysis, 2nd ed., Editors: G. Ertl, H. Knözinger, F. Schüth, J. Weitkamp, Wiley-VCH, Weinheim, 2008; Vol. 2, p. 740 . 


\section{Entry for the Table of Contents}

\section{FULL PAPER}

The role of Cu nanoparticles supported on $\mathrm{Mg}$-Al mixed oxide in the gas-phase ethanol condensation is studied. Results highlight the relevance of dehydrogenation in the 1-butanol productivity, reaching yields up to 12 times higher than those obtained with the parent Mg-Al. Working under reducing conditions, the yield is improved in $150 \%$. The proximity of $\mathrm{acid} / \mathrm{basic}$ and metal sites is required to obtain good results, discarding the activity of a mechanical mixture (Mg-Al $\left.+\mathrm{Cu} / \mathrm{SiO}_{2}\right)$.

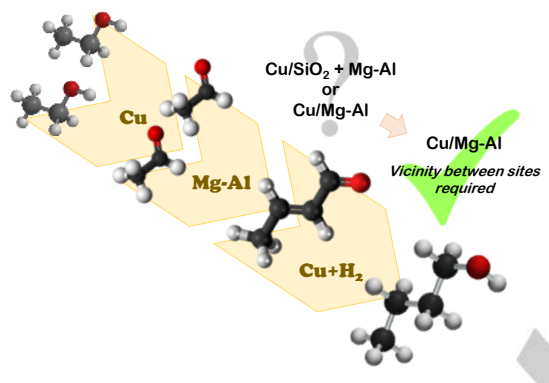

Jorge Quesada, Laura Faba, Eva Díaz and Salvador Ordóñez*

Page No. - Page No.

Title: Copper-basic sites synergic

effect on the ethanol

dehydrogenation and condensation

reactions 